\title{
ULTRASONIC ASSESSMENT OF TISSUE ANISOTROPY
}

\author{
WILLIAM D. O'BRIEN JR. ${ }^{\S}$ and JOHN E. OLERUD' \\ ${ }^{\S}$ Department of Electrical and Computer Engineering, University of Illinois, 1406 West Green Street, \\ Urbana, Il 61801 USA and 'Division of Dermatology, Department of Medicine, University of \\ Washington, Seattle, WA 98195 USA
}

\begin{abstract}
Two completely separate experiments using the Scanning Laser Acoustic Microscope, operating at an ultrasonic frequency of $100 \mathrm{MHz}$, assessed the attenuation coefficient and propagation speed of two anisotropic biological materials, viz., human Achilles tendon samples and bovine longissimus striated muscle samples. For the tendon samples, three separate locations were also evaluated (superior, medial and inferior). Anisotropy was evaluated by measuring the samples with the ultrasonic beam propagating either parallel or perpendicular to the tendon muscle fibers. Achilles tendons generally exhibited a greater anisotropy than did skeletal muscle, and for both materials, the parallel orientation of both attenuation coefficient and propagation speed were consistently greater that those of the perpendicular orientation.
\end{abstract}

\section{INTRODUCTION}

Ultrasonic propagation properties in biological tissues are not well understood [1] but are thought to be determined at the level of large molecules [2]. In muscle and connective tissues, for example, it is not clear to what degree the oriented structures contribute to sound propagation. These considerations are of interest in the clinical use of ultrasound since the composition and configuration of tissues changes during disease states (e.g., cirrhosis of the liver, certain muscular pathologies and degenerative joint diseases) as well as in normal physiologic processes (e.g., wound healing and fetal development).

Anisotropy has been reported in a number of oriented biological tissues in the low megahertz frequency range [3-9]. No work has been published characterizing muscle or tendon fiber anisotropy at higher frequencies. Therefore, this study investigates the acoustic anisotropy in bovine skeletal muscle and human Achilles tendon at high frequency $(100 \mathrm{MHz})$ using the Scanning Laser Acoustic Microscope.

\section{METHODS}

Thirty-six longissimus striated muscle specimens were obtained from eighteen individual beef carcasses 24 to 48 hours postmortem which had been placed in a $4^{\circ} \mathrm{C}$ refigerator within 2 hours postmortem. Specimens approximately $8 \times 3 \times 3 \mathrm{~mm}$ were placed on separate circular cork disks with muscle fibers either parallel or perpendicular to the cork surface and covered with O.C.T. All 36 corks were wrapped and labeled with specimen number and muscle fiber orientation, and stored in a $-70^{\circ} \mathrm{C}$ freezer.

Twenty-eight human Achilles tendon specimens were obtained from three locations of the same tendon, 12 specimens near the musculotendonous junction (superior), eight specimens midway down the tendon (medial) and eight specimens from near the calcaneal attachment (inferior). The human Achilles tendon was removed from a surgical specimen at the time of amputation and frozen at $-70^{\circ} \mathrm{C}$ until thawed for removing samples. Specimens approximately $8 \times 3 \times 3 \mathrm{~mm}$ were placed on separate circular cork disks with collagen fibers parallel or perpendicular to the cork surface and covered with O.C.T. All 28 corks were wrapped and labeled with specimen number and collagen fiber orientation, and stored in a $-70^{\circ} \mathrm{C}$ freezer after being shipped on dry ice to UIUC.

At the time of ultrasonic analysis, the cork to which the frozen specimen was attached was mounted in a microtome chuck for sectioning by a Lipshaw Cryostat Microtome (Lipshaw Manufacturing Company, Detroit, MI) at $-10^{\circ} \mathrm{C}$. The frozen section tissue thicknesses ranged from 70 to $140 \mu \mathrm{m}$ for muscle and from 25 to $150 \mu \mathrm{m}$ for tendon. The sectioned sample was trimmed into a rectangular piece of about $5 \times 1.5 \mathrm{~mm}$ and then transferred to the acoustic microscope stage for measurement of the ultrasonic propagation properties. The 
evaluations were conducted at room temperature $\left(\approx 22^{\circ} \mathrm{C}\right)$.

The two types of sample orientation are defined according to the relationship between muscle or tendon fiber orientation and the sound beam direction wherein parallel refers to the sound beam traveling parallel to the fibers and perpendicular refers to the sound beam traveling perpendicular to the fibers.

The Scanning Laser Acoustic Microscope (SLAM, Sonomicroscope 100, Sonoscan Inc., Bensenville, IL), operating at a frequency of $100 \mathrm{MHz}$, was used to determine the specimen's attenuation coefficient and propagation speed. The operational details of the SLAM have been published previously [10-12].

An insertion loss procedure was used to estimate the attenuation coefficient [10]. In principle, this procedure compares the received signal amplitude of the specimen of known thickness in the sound path with that of the reference medium, normal saline. The signals received from the subimage area $(400 \times 250$ $\mu \mathrm{m})$ are digitized to yield an average amplitude value (V). Six $V$ values were recorded for normal saline, the reference medium, and six $\mathrm{V}$ values were recorded at each of six separate specimen locations. An insertion loss (IL) value, in $\mathrm{dB}$, was estimated using

$$
\mathrm{L}=\mathrm{V}_{\mathrm{s}}-\left\langle\mathrm{V}_{\mathrm{r}}\right\rangle
$$

where $\left\langle V_{r}\right\rangle$ is the average of $V$ recorded from normal saline and $V_{S}$ represents individual $V$ values from the specimen. This process yields six IL values for each specimen thickness. Typically, three or four specimen thicknesses ranging from $70 \mu \mathrm{m}$ to $140 \mu \mathrm{m}$ for muscle and from $25 \mu \mathrm{m}$ to $150 \mu \mathrm{m}$ for tendon were used, and the slope of IL versus specimen thickness, via a linear least-squares fit (utilizing all $\mathrm{IL}$ thickness values) yielded the attenuation coefficient.

The spatial frequency domain technique was used to yield speed from the interference image [11]. For each specimen, three or four specimen thicknesses were analyzed, with each thickness yielding a mean speed value from the speed profile region within the specimen.
Anisotropy is defined as a percentage by

$$
\text { Anistropy }=\frac{\left|X_{\text {parallel }}-X_{\text {perpendicular }}\right|}{X_{\text {parallel }}+X_{\text {perpendicular }}} \times 100(2)
$$

where $X$ is either the parallel or perpendicular orientation of the specific ultrasonic propagation property.

Uncertainty of the estimates of attenuation coefficient and propagation speed from the SLAM have been assessed for solutions of known acoustic properties [12]. With a homogenous medium, the accuracy (proximity to the true value) was $\pm 2.9 \%$ and the precision (reproducibility of successive independent measurements) was $\pm 0.4 \%$ for speed; for attenuation coefficient, accuracy and precision were $\pm 12 \%$ and $\pm 15 \%$, respectively. With heterogeneous samples of normal canine skin and wound tissue, the speed and attenuation coefficient precision were $\pm 1.7 \%$ and $\pm 16 \%$, respectively.

The analysis of variance (ANOVA) was used to determine the probability that the means of several treatment groups of scores deviated from one another merely by sampling error. For the tendon data, the Scheffé's Test was used if the ANOVA achieved a $\mathrm{p}<0.05$ to determine which pairs of means were significantly different. Results were considered statistically significant when the probability of error was less than the 0.05 level. All statistical tests were performed with the SAS Software (Cary, NC).

\section{RESULTS}

Bovine longissimus striated muscle fiber orientation was observed to have a significant effect on ultrasonic propagation properties (see Table 1). Propagation speed was consistently higher for parallel orientation ( $p<0.0001$ ) with average anisotropy approximately $0.63 \%$. Attenuation coefficient at $100 \mathrm{MHz}$ was consistently higher for parallel orientation $(\mathrm{p}<$ 0.0001 ) with average anisotropy approximately $31.7 \%$. 
Table 1

\begin{tabular}{ccc}
\hline \multicolumn{3}{c}{$\begin{array}{c}\text { Mean } \pm \text { standard deviation of bovine longissimus stri- } \\
\text { ated muscle }\end{array}$} \\
\hline Orientation & $\begin{array}{c}\text { Propagation } \\
\text { Speed } \\
(\mathrm{m} / \mathrm{s})\end{array}$ & $\begin{array}{c}\text { Attenuation } \\
\text { Coefficient } \\
(\mathrm{dB} / \mathrm{cm})\end{array}$ \\
\hline Parallel & $1619 \pm 9$ & $873 \pm 216$ \\
Perpendicular & $1599 \pm 8$ & $454 \pm 133$ \\
\hline
\end{tabular}

Human Achilles tendon fiber orientation was observed to have a significant effect on ultrasonic propagation properties (see Table 2). Propagation speed was consistently higher for

Table 2

\begin{tabular}{|c|c|c|}
\hline \multicolumn{3}{|c|}{ Mean \pm standard deviation of human Achilles tendon } \\
\hline $\begin{array}{l}\text { Orientation/ } \\
\text { Location }\end{array}$ & $\begin{array}{l}\text { Propagation } \\
\text { Speed** } \\
\text { (m/s) }\end{array}$ & $\begin{array}{l}\text { Attenuation } \\
\text { Coefficient* } \\
(\mathrm{dB} / \mathrm{cm})\end{array}$ \\
\hline $\begin{array}{l}\text { Parallel } \\
\text { Superior }\end{array}$ & $\begin{array}{c}1886 \pm 168 \\
(\mathrm{a}, \mathrm{b}, \mathrm{c}, \mathrm{d})\end{array}$ & $\begin{array}{c}1144 \pm 343 \\
(a, b)\end{array}$ \\
\hline $\begin{array}{l}\text { Parallel } \\
\text { Medial }\end{array}$ & $\begin{array}{c}1932 \pm 158 \\
(\mathrm{e}, \mathrm{f}, \mathrm{g}, \mathrm{h})\end{array}$ & $\begin{array}{c}1122 \pm 440 \\
(\mathrm{c}, \mathrm{d})\end{array}$ \\
\hline $\begin{array}{l}\text { Parallel } \\
\text { Inferior }\end{array}$ & $\begin{array}{c}2139 \pm 169 \\
(\mathrm{a}, \mathrm{e}, \mathrm{i}, \mathrm{j}, \mathrm{k})\end{array}$ & $\begin{array}{c}1099 \pm 81 \\
(e, f)\end{array}$ \\
\hline $\begin{array}{l}\text { Perpendicular } \\
\text { Superior }\end{array}$ & $\begin{array}{c}1673 \pm 53 \\
(b, f, i)\end{array}$ & $\begin{array}{c}282 \pm 132 \\
(a, c, e)\end{array}$ \\
\hline $\begin{array}{l}\text { Perpendicular } \\
\text { Medial }\end{array}$ & $\begin{array}{c}1665 \pm 73 \\
(c, g, j)\end{array}$ & $\begin{array}{c}348 \pm 97 \\
(b, d, e)\end{array}$ \\
\hline $\begin{array}{l}\text { Perpendicular } \\
\text { Inferior }\end{array}$ & $\begin{array}{c}1686 \pm 67 \\
(d, h, k)\end{array}$ & $655 \pm 120$ \\
\hline
\end{tabular}

*ANOVA yielded a statistically significant finding $(p<0.001)$ for propagation speed and attenuation coefficient. For these quantities, the matched letters in parentheses in their respective columns represent pairs of means that are significantly different $(p<0.05)$ as determined by the Scheffe's test. For example, for propagation speed, " $\mathrm{b}$ " denotes the parallel and perpendicular orientations for the superior location are statistically significantly different. parallel orientation at each of the three locations with average anisotropies approximately $5.98 \%, 7.42 \%$ and $11.8 \%$, respectively, for superior, medial and inferior locations. Attenuation coefficient at $100 \mathrm{MHz}$ was consistently higher for parallel orientation at each of the three locations with average anisotropies approximately $60.5 \%, 52.7 \%$ and $25.3 \%$, respectively, for superior, medial and inferior locations.

\section{DISCUSSION}

A consistant observation is the significant anisotropy of ultrasonic propagation properties with fiber orientation at $100 \mathrm{MHz}$ exhibited by both bovine striated muscle and human Achilles tendon. Consistently larger values of propagation speed and attenuation coefficient were measured for the parallel orientation. Good agreement exists between present results and those of previous anisotropy studies of striated muscle and Achilles tendon at lower frequencies (see Tables 3-5). The striated muscle anisotropy of propagation speed and attenuation coefficient appears to be slightly greater at the lower frequencies whereas the Achilles tendon anisotropy of propagation speed does not appear to be dependent on frequency. No reliable lower frequency data could be found for which the anisotropy could be determined for Achilles tendon attenuation coefficient.

\section{Table 3}

Comparison of attenuation coefficient, $\mathrm{A} / \mathrm{f}(\mathrm{dB} / \mathrm{cm}$ $\mathrm{MHz}$ ) anistropy observations for striated muscle

\begin{tabular}{ccccc}
\hline $\begin{array}{c}\text { Freq } \\
\begin{array}{c}\text { Freq Range } \\
\text { (MHz) }\end{array}\end{array}$ & $\begin{array}{c}\text { A/f } \\
\text { Para }\end{array}$ & $\begin{array}{c}\text { Avf } \\
\text { Perp }\end{array}$ & $\begin{array}{c}\text { Anisotropy } \\
(\%)\end{array}$ & \\
\hline 3.4 & 1.53 & 0.68 & 38.7 & {$[3]$} \\
$1-8$ & 2.9 & 1.1 & 45.0 & {$[7]$} \\
2 & 1.40 & 0.49 & 48.2 & {$[9]$} \\
4 & 1.12 & 0.49 & 39.1 & {$[9]$} \\
7 & 1.23 & 0.53 & 39.8 & {$[9]$} \\
5 & 3.1 & 0.9 & 55.0 & {$[8]$} \\
20 & 3.1 & 1.3 & 40.9 & {$[8]$} \\
100 & 8.73 & 4.54 & 31.7 & \\
\hline
\end{tabular}




\section{Table 4}

Comparison of propagation speed $(\mathrm{m} / \mathrm{s})$ anistropy observations for striated muscle

\begin{tabular}{ccccc}
$\begin{array}{c}\text { Freq } \\
\begin{array}{c}\text { Freq Range } \\
\text { (MHz) }\end{array}\end{array}$ & $\begin{array}{c}c \\
\text { Para }\end{array}$ & $\begin{array}{c}\text { c } \\
\text { Perp }\end{array}$ & $\begin{array}{c}\text { Anisotropy } \\
(\%)\end{array}$ & \\
\hline $4-12$ & 1592 & 1576 & 0.51 & {$[5]$} \\
5 & 1561 & 1551 & 0.32 & {$[6]$} \\
5 & 1557 & 1548 & 0.29 & {$[6]$} \\
100 & 1619 & 1599 & 0.63 & \\
\hline
\end{tabular}

Table 5

Comparison of propagation speed $(\mathrm{m} / \mathrm{s})$ anistropy observations for Achilles tendon

\begin{tabular}{ccccc}
\hline $\begin{array}{c}\text { Freq } \\
(\mathrm{MHz})\end{array}$ & $\begin{array}{c}\mathrm{c} \\
\text { Para }\end{array}$ & $\begin{array}{c}\mathrm{c} \\
\text { Perp }\end{array}$ & $\begin{array}{c}\text { Anisotropy } \\
(\%)\end{array}$ & \\
\hline 5 & 2020 & 1670 & 9.49 & {$[4]$} \\
& & & & \\
100 & 1886 & 1673 & 5.98 & Superior \\
100 & 1932 & 1665 & 7.42 & Medial \\
100 & 2139 & 1686 & 11.8 & Inferior \\
\hline
\end{tabular}

Ultrasonic propagation speed and attenuation coefficient anisotropy of striated muscle and Achilles tendon have been demonstrated by others [3-9] in the lower megahertz frequency range and this work has shown that the anisotropy is present at $100 \mathrm{MHz}$. Further, others have shown ultrasonic propagation properties anisotropy in myocardium whereas no anisotropy was present in liver [13]. The mechanism(s) of anisotropy are attributed to tissue orientation but the actual cause(s) are yet to be understood.

\section{REFERENCES}

[1] J. F. Greenleaf (ed.), Tissue Characterization with Ultrasound, volumes I and II, CRC Press, Boca Raton, FL, 1987

[2] F. Dunn and W. D. O'Brien, Jr. (eds.), Ultrasonic

Biophysics, Dowden, Hutchinson \& Ross, Inc.,

Stroudsburg, PA, 1976.
[3] S. Colombati and S. Petralia, "Assorbimento di ultrasuoni in tessuti animali," Ric Sci, 20, 71-78, 1950.

[4] B. K. Hoffmeister, S. M. Handley, E. D. Verdonk, S. A. Wickline, and J. G. Miller, "Estimation of the elastic coefficient $c_{13}$ of fixed tendon and fixed myocardium," J Acoust Soc Am, 27, 3171-3176, 1995.

[5] D. E. Goldman and J. R. Richards, "Measurement of high-frequency sound velocity in mammalian soft tissues," J Acoust Soc Am, 26, 981-983, 1954.

[6] C. R. Mol and P. A. Breddels, "Ultrasound velocity in muscle," J Acoust Soc Am, 71, 455-461, 1982.

[7] D. K. Nassiri, D. Nicholas, and C. R. Hill, "Attenuation of ultrasound in skeletal muscle," UItrasonics, 17, 230-232, 1979.

[8] V. Roberjot, P. Laugier and G. Berger, "Anisotropy in bovine skeletal muscle in vitro: frequency dependent attenuation and backscatter coefficient over a wide range of frequencies," 1994 IEEE Ultrasonics Symposium Proceedings, pp 1467-1470, 1994

[9] D. Shore, M. O. Woods, and C. A. Milles, "Attenuation of ultrasound in post rigor bovine skeletal muscle," Ultrasonics, 24, 81-87, 1986.

[10] K. M. U. Tervola, S. G. Foster, and W. D. O'Brien, Jr., "Attenuation coefficient measurement technique at $100 \mathrm{MHz}$ with the scanning laser acoustic microscope," IEEE Trans Sonics Ultrason, SU32, 259-265, 1985.

[11] K. M. U. Tervola and W. D. O'Brien, Jr., "Spatial frequency domain technique: An approach for analyzing the scanning laser acoustic microscope interferogram images," IEEE Trans Sonics Ultrason, SU-32, 544-554, 1985.

[12] D. L. Steiger, W. D. O'Brien Jr., J. E. Olerud, M.A. Riederer-Henderson, and G. F. Odland, "Measurement uncertainty assessment of the scanning laser acoustic microscope and application to canine skin and wound," IEEE Trans Ultrason Ferroelec Freq. Control, 32, 741-748, 1988.

[13] J. G. Mottley and J. G. Miller, "Anisotropy of the ultrasonic attenuation in soft tissues: measurements in vitro," J Acoust Soc Am, 88, 1203-1210, 1990.

\section{ACKNOWLEDGMENTS}

Supported by NIH CA09067, NIH HD21687, the US Department of Agriculture and the $\mathrm{Na-}$ tional Live Stock and Meat Board. 